\title{
PEMBELAJARAN BIPA DENGAN APLIKASI AWAN ASA BERBASIS PENGENALAN LINTAS BUDAYA
}

\author{
Prahoro Yudo Purwono", Prima Vidya Asteria ${ }^{2}$ \\ ${ }^{1}$ Program Studi Sastra Jerman, Fakultas Bahasa dan Seni, Universitas Negeri \\ Surabaya, Surabaya, Jawa Timur \\ ${ }^{2}$ Program Studi Pendidikan Bahasa dan Sastra Indonesia, Fakultas Bahasa dan Seni, \\ Universitas Negeri Surabaya, Surabaya, Jawa Timur \\ drpurwono369@gmail.com
}

\begin{abstract}
ABSTRAK:Pembelajaran bahasa Indonesia sebagai bahasa asing sudah menjadi tren dan kebutuhan di era saat ini. Maka, inovasi pembelajaran bahasa Indonesia sangat penting dilakukan sesuai dengan level pembelajar. Hal ini bertujuan untuk mempermudah pemahaman pembelajar dalam menguasai bahasa Indonesia. Salah satu caranya adalah dengan pembelajaran terintegrasi berbasis pengenalan lintas budaya. Oleh karena itu, digagaslah media AWAN ASA. Aplikasi ini berbasis software macromedia flash sehingga mudah untuk diaplikasikan dan interaktif bagi pengguna. Metode penelitian yang digunakan adalah penelitian deskriptif kuantitatif persentase. Metode dan media aplikasi AWAN ASA yang dipakai dalam pembelajaran bahasa Indonesia sebagai bahasa asing terintegrasi dengan pengenalan lintas budaya, didapati hasil keterampilan menulis siswa cukup bagus, dengan rata-rata mendapatkan nilai di kisaran 70 dan mampu menulis konjungsi dari 8-18 kata. Dapat disimpulkan bahwa metode dan aplikasi yang digunakan untuk mahasiswa BIPA UNESA benar-benar sesuai bagi mereka, serta metode dan media yang dipakai mampu meningkatkan pemahaman dan pengetahuan mereka mengenai bahasa dan kebudayaan Indonesia.
\end{abstract}

KATA KUNCI: Aplikasi; Bahasa Asing; Lintas Budaya;Pembelajaran.

\section{BIPA'S LEARNING WITH AWAN ASA APPLICATION BASED ON CROSS-CULTURAL UNDERSTANDING}

\begin{abstract}
Learning Indonesian as a foreign language has become a trend and a necessity in the current era. Thus, it is very important to make innovations in learning Indonesian based on the level of the learner. This research aims to facilitate the learner's understanding of mastering Indonesian through integrated learning based on cross-cultural introduction. Therefore, the AWAN ASA media was initiated. AWAN ASA is an Indonesian language learning application which is integrated with wayang stories as Indonesian culture. The research method used quantitative descriptive research. The method and media of the AWAN ASA application is integrated with cross-cultural introduction, which was found that the results of students' writing skills were quite good, with an average score in the range of 70 and being able to write conjunctions of 8-18 words. It means, the methods and applications used in learning language for BIPA UNESA students are really suitable for them. Therefore, the methods and media can improve understanding and their knowledge of Indonesian language and culture.

KEYWORDS:Application; Cros-Cultural Understanding; Foreign Language; Learning.

\begin{tabular}{llll}
\hline Diterima: & Direvisi: & Disetujui: & Dipublikasi: \\
2021-01-06 & 2021-01-12 & 2021-01-14 & 2021-03-28
\end{tabular}

Pustaka : Purwono, P., \& Asteria, P. (2021). PEMBELAJARAN BIPA DENGAN APLIKASI AWAN ASA BERBASIS PENGENALAN LINTAS BUDAYA. Fon : Jurnal Pendidikan Bahasa dan Sastra Indonesia, 17(1), 97-107. doi:https://doi.org/10.25134/fjpbsi.v17i1.3892
\end{abstract}

\section{PENDAHULUAN}

Bahasa asing merupakan sarana untuk berkomunikasi antar manusia antar negara, sehingga belajar bahasa asing dianggap sebagai bahasa pemersatu dan dapat digunakan untuk keperluan komunikasi (Harawati, 2019). Bahkan dapat dikatakan bahwa belajar bahasa asing merupakan suatu esensi hidup dalam kehidupan bermasyarakat di era modern (Malinovska et al, 2017). 
Lebih lanjut, dengan belajar dan menguasai bahasa asing juga dapat menjadi sarana untuk meningkatkan kemampuan diri sendiri, memahami budaya lain, membangun sikap inisiatif diri, mampu beradaptasi dan berinteraksi dalam tim dari berbagai latar belakang bahasa dan budaya yang berbeda, serta mampu untuk berpikiran terbuka dan berwawasan luas (Kondrateva et al, 2015). Dalam realitanya, bahasa asing di dunia ini sangat banyak, karena masing-masing negara memiliki bahasanya sendiri, tak terkecuali bahasa Indonesia.

Pembelajaran bahasa Indonesia sebagai bahasa asing di saat ini tengah berkembang pesat. Tidak hanya di kawasan ASEAN saja pembelajaran bahasa Indonesia diterapkan, tetapi sudah merambah ke negara-negara di benua Eropa. Bahkan bahasa Indonesia juga menjadi objek yang dipelajari di Finlandia (Arumdyahsari et al, 2016). Pemaparan tersebut diperkuat dengan pernyataan Artaewee (2018) yang menyatakan bahwa bahasa Indonesia merupakan bahasa ketiga di negara Thailand. Kehadiran program BIPA (Bahasa Indonesia Bagi Penutur Asing) di beberapa universitas di Indonesia juga menjadi bukti bahwa bahasa Indonesia sudah mendunia. Sehingga pembelajaran bahasa Indonesia sebagai bahasa asing sudah menjadi tren dan kebutuhan di era saat ini.

Maka, inovasi pembelajaran bahasa Indonesia sebagai bahasa asing sesuai dengan level pembelajar sangat penting dilakukan. Tujuannya adalah untuk mempermudah pemahaman pembelajar dalam menguasai bahasa Indonesia. Salah satu caranya adalah dengan pembelajaran terintegrasi berbasis pengenalan lintas budaya.

Pembelajaran bahasa asing berbasis lintas budaya bahasa target sebenarnya bukan hal yang benar-benar baru. Sebelumnya telah ada penelitian terkait pembelajaran bahasa asing dan juga pemahaman lintas budaya yang dapat mendorong kemampuan dan motivasi untuk belajar bahasa asing.

Penelitian pertama adalah penelitian dari Pourfeiz (2016) yang berjudul “ $A$ Cross-sectional Study of Relationship between Attitudes toward Foreign Language Learning and Academic Motivation". Hasil penelitian mengungkapkan hubungan timbal balik antara belajar bahasa asing dengan motivasi akademik. Khususnya dalam hal karakter, tingkah laku dalam komponen penilaian afektif/evaluatif dengan pendekatan belajar bahasa asing sebagai pemrediksi terbaik untuk motivasi akademik. Lebih lanjut, meskipun kemampuan bahasa asing berkorelasi positif dengan faktor internal maupun eksternal dalam pembentukan motivasi akademik, namun tingkah laku tidak berasosiasi dengan penurunan atau kelahiran suatu motivasi. Lebih lanjut, dalam penelitian dijelaskan bahwa dengan metode AFLL mampu memprediksi hingga $17 \%$ tentang motivasi akademik terkait korelasinya dengan sikap dalam belajar bahasa asing, selain itu, dalam perlakuan kedua didapati hasil hingga $25 \%$ terkait motivasi akademik dari faktor internal, $13 \%$ dari faktor eksternal, dan 8\% tanpa motivasi. Dengan demikian dapat disimpulkan bahwa sikap tidak berkorelasi dengan pembelajaran bahasa sebagai bahasa kedua maupun sebagai bahasa asing.

Penelitian kedua berjudul "Innovating a constructivist learning model to instill cultural diversity respect into youths in a Thai tourism community", (Srisawad dkk., 2016). Hasil penelitian mengungkapkan bahwa, sebelum partisipasi mereka dalam penelitian ini, para pemuda memiliki rasa hormat terhadap keanekaragaman budaya yang rendah. Dalam sembilan bulan aksi belajar mereka, para pemuda memupuk rasa hormat mereka ke tingkat yang mereka 
tentukan sebelumnya. Dari pembelajaran mereka muncul model pembelajaran konstruktivisme inovasi. Dalam LCULTURA atau Learn-to Cultivate Cultures Model, anak-anak muda terlibat dalam sembilan langkah spiral mengambil tantangan, memeriksa stok, merencanakan belajar mandiri, mencari informasi baru, menyortir informasi-informasi, menyampaikan informasi, mendapatkan umpan balik, merefleksikan pengalaman belajar dan menciptakan kebiasaan. Pakar komunitas dan para peneliti berperan dalam perancah proses belajar mereka sebagai motivator, stimulator, penantang, penasihat, sumber daya manusia dan fasilitator. Sebelum penelitian dilakukan, para pemuda memiliki skor rendah (15\%) dalam hal rasa hormat terhadap keanekaragaman budaya. Apresiasi mereka terhadap budaya sendiri, perlindungan diri dan budaya masyarakat, serta penghargaan terhadap budaya lain masing-masing hanya $20 \%, 14 \%$ dan $13 \%$. Setelah penelitian dilakukan, hasil yang didapat berupa peningkatan skor dari 15 persen menjadi 80 persen sesuai yang ditargetkan.

Dari dua penelitian di atas, dapat diketahui bahwa pengembangan model inovatif pembelajaran bahasa dan budaya sangat penting dilakukan. Selain untuk meningkatkan hasil pembelajaran, keberadaan budaya sebagai aset bangsa juga perlu diajarkan untuk memperkuat eksistensi kebudayaan dan membantu para penutur asing lebih menghargai keberadaan budaya bahasa target yang mereka pelajari.

Hingga saat ini, media pembelajaran bahasa Indonesia sebagai bahasa asing yang inovatif dan terintegrasi budaya masih sangat terbatas. Dalam praktiknya, ternyata pengajaran bahasa Indonesia bagi penutur asing masih memiliki beberapa kekurangan juga, salah satunya adalah mengenai media pembelajaran yang terbatas. Padahal, media dalam pembelajaran bahasa asing merupakan suatu hal yang sangat penting (Oroujlou, 2012).

Media bagi pembelajar bahasa asing umumnya bertindak sebagai bahan ajar, yang kemudian menjadi sumber informasi dan alat bantu untuk memahami materi pembelajaran. Di samping itu, keberadaan media pembelajaran juga terbukti efektif untuk meningkatkan hasil pembelajaran (Suryaman, 2010), sehingga keberadaannya mutlak diperlukan.

Berdasarkan observasi awal di beberapa situs, didapati bahwa media memang menjadi kendala utama dalam pembelajaran bahasa Indonesia sebagai bahasa asing berbasis lintas budaya. Dalam hal ini, akan lebih baik jika pembelajaran bahasa Indonesia bisa melibatkan media pembelajaran yang diintegrasikan dengan budaya bahasa target sehingga mampu mempercepat penguasaan bahasa yang dipelajari. Menurut Bobykina (2015), pembelajaran bahasa asing memang seharusnya berbasis pengenalan lintas budaya, karena banyak sekali unsur-unsur kebudayaan dalam pembelajaran bahasa. Hal ini diperkuat dengan pendapat Deng (2017) yang menyatakan belum ada studi yang menyatukan pembelajaran formal dan informal dalam mendukung pembelajaran bahasa asing terintegrasi pengenalan lintas budaya, padahal hal ini seharusnya dilakukan.

Lebih lanjut, permasalahan ini didukung dengan fakta di lapangan, khususnya dalam pembelajaran BIPA UNESA (Universitas Negri Surabaya). Berdasarkan hasil pengamatan peneliti, mahasiswa BIPA UNESA masih mengalami kesulitan dalam menulis dan merangkai kata. Selain itu, proses pembelajaran sangat jarang menggunakan media pembelajaran dan model pengenalan lintas budaya, sehingga pembelajaran kurang efektif, karena 
tujuan pembelajaran tidak tercapai dengan optimal.

Dengan demikian, kebutuhan model pembelajaran dengan media berbasis lintas budaya perlu untuk diterapkan. Media pembelajaran yang diterapkan akan lebih baik jika berbasis teknologi (Klimova, 2020). Penggunaan media pembelajaran berbasis teknologi juga merupakan salah satu cara agar pembelajaran bahasa asing menjadi lebih mudah dan lebih menyenangkan bagi pembelajar (Bilyalova, 2017). Selain itu, mengoperasikan teknologi — terutama digital - merupakan kemampuan dasar yang wajib dimiliki di abad ke-21 ini, baik dalam pengajaran maupun pembelajaran (Gonzalez-Acevedo, 2016).

Berdasarkan permasalahanpermasalahan yang telah dikemukakan dan dibahas sebelumnya, maka peneliti tertarik untuk melakukan penelitian menggunakan media pembelajaran berbasis pengenalan lintas budaya bernama AWAN ASA. Penelitian ini berfokus untuk mendeskripsikan bagaimana proses, hasil pembelajaran, serta respon pembelajar terhadap pembelajaran bahasa Indonesia dengan Aplikasi AWAN ASA berbasis pengenalan lintas budaya.

\section{METODE}

Penelitian yang digunakan termasuk dalam penelitian deskriptif kuantitatif persentase (Sugiyono, 2008). Dalam hal ini, peneliti mengambil data di lapangan selanjutnya hasil yang berupa angkaangka persentase dideskripsikan.

Subjek penelitian adalah mahasiswa BIPA Universitas Negeri Surabaya. Dalam penelitian ini, terdapat 7 orang mahasiswa BIPA UNESA yang menjadi subjek penelitian dengan rincian 6 di antaranya perempuan dan 1 orang lakilaki. Mereka berasal dari berbagai negara yang berbeda, mulai dari Latvia, Jepang, China, Korea Selatan, dan Azerbaijan.
Lokasi penelitian terletak di Universitas Negeri Surabaya.

Materi yang diajarkan adalah keterampilan menulis dengan fokus utama berupa penggunaan konjungsi dalam merangkum sebuah cerita rakyat Indonesia yang telah dipelajari. Kemudian, pengumpulan data dalam penelitian ini menggunakan teknik pengumpulan data primer. Data primer didapatkan dengan cara menilai hasil tulisan mahasiswa asing yang belajar bahasa Indonesia di UNESA serta pengisian angket untuk mengetahui respon mahasiswa terhadap proses pembelajaran menggunakan media. Data yang didapat kemudian dikumpulkan dan digunakan untuk menganalisis secara mendalam. Analisis tersebut dilakukan secara deskriptif (persentase/kuantitatif (Sugiyono, 2008) untuk kemudian dijadikan landasan dalam menjawab rumusan masalah yang ada dalam penelitian. Teknik analisis data dalam penelitian ini.

Pengumpulan data, data-data yang telah didapat di lapangan berupa lembar kerja pembelajar dikumpulkan untuk selanjutnya dinilai dan dicatat dalam tabel.

Reduksi data, di mana data yang diperoleh berupa nilai-nilai dari hasil tulisan pembelajardihitung berapa persentasenya, kemudian dibahas dan diselaraskan dengan konsep penelitian yang relevan dan teori-teori yang telah ada untuk menentukan keberhasilan penelitian.

Penarikan kesimpulan, bertujuan untuk menjawab rumusan masalah. Di dalam artikel ini diruaikan secara detail mengenai hasil akhir yang diperoleh dari pengujian yang ada di lapangan dan hasil nilai tulisan mahasiswa.

\section{HASIL DAN PEMBAHASAN}

Proses pembelajaran dilakukan dengan tahapan sebagai berikut: 
Peneliti menjelaskan tujuan pembelajaran yang sudah disusun dalam Silabus dan Rencana Pelaksanaan Pembelajaran (RPP).

Peneliti menjelaskan materi awal keterampilan menulis materi konjungsi (kata hubung).

Peneliti membagi 7 mahasiswa ke dalam 3 kelompok kecil lalu memberikan aplikasi AWAN ASA kepada mahasiswa agar siswa menginstal di laptop masingmasing sehingga pelaksanaan pembelajaran akan lebih mudah.

Peneliti menjelaskan caramenggunakan media pembelajaran aplikasi AWAN ASA.

Mahasiswa menggunakan media pembelajaran aplikasi AWAN ASA secara berkelompok. Mereka bisa mengakses materi-materi pembelajaran bahasa Indonesia dan juga menonton video animasi cerita wayang Indonesia "Bima Bungkus".

Peneliti menjelaskan kembali cerita "Bima Bungkus" dan berdiskusi dengan mahasiswa terkait cerita wayang tersebut, terutama mendiskusikan lakon wayang dihubungkan dengan pembelajaran bahasa dan pengenalan lintas budaya.

Di akhir pembelajaran, peneliti meminta mahasiswa untuk menulis sinopsis dari cerita wayang tersebut dan mengisi angket untuk mengetahui respon mereka terhadap proses pembelajaran dengan media AWAN ASA.

Selanjutnya, peneliti menilai hasil tulisan mereka dan menghitung berapa jumlah konjungsi yang mereka pakai, kemudian baik nilai maupun jumlah konjungsi yang mereka tulis dirata-rata. Berikut tabel hasil penilaian masingmasing mahasiswa.

Tabel 1 Hasil Pembelajaran

\begin{tabular}{ccccc}
\hline No & Nam & Asal & Jumlah & Nila \\
$\cdot$ & a & Negara & Konjungs & i \\
& & & i &
\end{tabular}

\begin{tabular}{|c|c|c|c|c|}
\hline 1 & B1 & Latvia & 18 & 70 \\
\hline 2 & B2 & China & 8 & 75 \\
\hline 3 & B3 & China & 8 & 75 \\
\hline 4 & B4 & China & 11 & 75 \\
\hline 5 & B5 & Jepang & 11 & 75 \\
\hline 6 & B6 & $\begin{array}{c}\text { Azerbaija } \\
n\end{array}$ & 11 & 75 \\
\hline 7 & B7 & $\begin{array}{l}\text { Korea } \\
\text { Selatan }\end{array}$ & 18 & 70 \\
\hline & & Rata & 12 & 74 \\
\hline
\end{tabular}

seterusnya.

Dari tabel 1 di atas, terdapat perbedaan jumlah konjungsi yang ditulis dan juga nilai yang didapatkan oleh masing-masing mahasiswa. Hasil rata-rata nilai yang didapat oleh mahasiswa dalam tulisannya adalah 74 . Hasil nilai rata-rata ini menunjukkan bahwa hasil pembelajaran cukup berhasil karena mahasiswa mampu untuk menceritakan kembali cerita wayang yang telah mereka tonton dalam bentuk ringkasan. Kemudian, dari segi materi pembelajaran yaitu konjungsi, rata-rata konjungsi yang mampu mereka tulis adalah 12 konjungsi pertulisan, dari target normal jumlah konjungsi yang sebaiknya ditulis yaitu minimal 10. Berikut disajikan pembahasan penggalan tulisan mahasiswa B1 hingga B7 untuk mempertajam analisis. Data tidak ditampilkan keseluruhan karena peneliti hanya akan berfokus membahas jenis-jenis konjungsi dalam tulisan data, di mana pada data lengkap, terdapat pengulangan jenis konjungsi yang ditulis.

Analisis pertama adalah penggalan hasil tulisan dari mahasiswa B1 dari Latvia. Data ditampilkan sebagai berikut: (B1, Latvia) Raja Pandu dan Dewi Kunthi sedih karena anaknya lahir dibungkus. 
Sudah 8 tahun begitu, sehingga Kurawa menawarkan diri menolong. Tetapi Kurawa memiliki maksud jahat, yaitu untuk membunuh Bima. Sayangnya, rencana mereka gagal. Raja Pandu dan Dewi Kunthi yang semakin resah akhirnya menemui Begawan Abiyasa untuk meminta bantuan. Begawan Abiyasa menyuruh Gajah Sena untuk membantu Raja Pandu. Gajah Sena mengerahkan seluruh tenaganya dan berhasil membuka bungkus tersebut. Namunia akhirnya mati, dan berubah menjadi cahaya. Sesaat setelah bungkus terbuka, cahaya itu menyatu dengan si bayi yang diberi nama Bima.

Dari data 1 , konjungsi yang ditulis oleh mahasiswa B1 dari Latvia, yaitu "tetapi", "sehingga", "sayangnya", "sesaat", dan "yang". Kelima konjungsi ini ditulis beberapa kali dalam keseluruhan sinopsis yang ditulis mahasiswa B1, sehingga membuat teks lebih padu dan mudah dipahami.

Selanjutnya disajikan penggalan tulisan data 2 dari mahasiswa B2 asal China.

(B2, China) Raja Pandu dan Dewi Kunthi menangis siang malam. Mereka sedih karena anaknya tidak normal. Tetapi mereka kemudian pergi bertemu Begawan Abiyasa untuk meminta bantuan.Begawan Abiyasa berkata harus menemui Gajah Sena. Raja Pandu dan Dewi Kunthi senang. Kemudian mereka pergi menemui Gajah Sena.

Dari data 2, konjungsi yang ditulis oleh mahasiswa B2 dari China, yaitu "dan", "kemudian", dan "tetapi". Keragaman jenis konjungsi yang ditulis oleh mahasiswa B2 asal China ini masih sangat rendah, karena terdapat total 8 konjungsi dari keseluruhan sinopsisnya. Dan dari 8 konjungsi, 3 konjungsi yang terdapat dalam penggalan data menjadi yang paling sering muncul dalam tulisannya.
Kemudian, analisis berlanjut ke data 3 sebagai berikut:

(B3, China) Gajah Sena mau menolong Raja Pandu dan Dewi Kunthi. Kemudian dia pergi ke hutan. Dia berhasil membuka bungkus, tetapi dia mati. Akhirnya, dia menyatu dengan si bayi dan diberi nama Bima.

Konjungsi yang ditulis oleh mahasiswa B3 dari China yaitu "dan", "kemudian", "akhirnya", dan "tetapi". Keempat konjungsi tersebut paling sering muncul dan digunakan dalam sinopsis mahasiswa B3. Secara keseluruhan, penggunaan konjungsi sudah tepat dan sesuai, meski kepaduan antar kalimat dalam teks kurang.

Selanjutnya pada data ke-4 ditampilkan analisis sebagai berikut:

(B4, China) Kemudian Raja Pandu dan Dewi Kunthi pergi menemui Begawan Abiyasa. Mereka datang untuk meminta bantuan. Mereka diberi tahu bahwa Gajah Sena bisa membantu membuka Bungkus itu. Lalu Gajah Sena pergi ke hutan dan mengerahkan semua tenaganya untuk membuka Bungkus itu. Bungkus pun terbuka dan Gajah Sena pun mati. Iakemudian berubah menjadi cahaya, lalu menyatu dengan bayi tersebut. Bayi tersebut pun mewarisi kekuatan Gajah Sena.

Dari satu penggalan paragraf hasil tulisan mahasiswa B4, terdapat 3 konjungsi yang digunakan yaitu "kemudian", "dan", dan "lalu" dan dituliskan sebanyak 7 kali untuk merangkai kalimat menjadi satu paragraf yang utuh dan padu. Ini menunjukkan kemampuan menulis mahasiswa tersebut semakin meningkat dan mulai memahami bagaimana konsep menulis yang baik dan padu dalam belajar bahasa asing.

Dapat ditunjukkan pula hasil tulisan dari mahasiswa lain yang menuliskan beberapa konjungsi yang berbeda dari yang dituliskan oleh mahasiswa B4, 
seperti tulisan dari mahasiswa B5 dari Jepang sebagai berikut:

(B5, Jepang) Anak raja Pandu dan Dewi Kunthi terbungkus selama 8 tahun.Tidak ada senjata yang bisa membukanya. Kerajaan gempar, bahkan langit juga. Banyak yang mencoba membuka bungkus itu, tetapi gagal. Kurawa menawarkan diri untuk menolong. Sayangnya mereka memiliki maksud jahat. Mereka mau membunuh si bungkus. Namun Kurawa juga gagal membuka bungkus itu.

Tulisan mahasiswa B5 memiliki 4 konjungsi yaitu "dan", "tetapi", "sayangnya", dan "namun". 4 konjungsi ini membuat kalimat yang ditulis menjadi lebih padu. Sehingga kemampuan menulis dari mahasiswa B5 menjadi lebih baik.

Sedangkan pada data ke-6, berikut disajikan penggalan tulisan dan hasil analisis.

(B6, Azerbaijan) Gajah Sena datang ke hutan untuk membuka bungkus. Dengan seluruh kekuatannya, Gajah Sena membuka bungkus itu. Namun, Gajah Sena akhirnya mati. Kemudian ia menyatu dengan si bayi.

Dari data ke-6 milik mahasiswa B6, terdapat dua konjungsi yang digunakan, yaitu "namun" dan "kemudian". Penggunaan dua konjungsi tersebut selaras dengan kebutuhan kata hubung yang sesuai untuk menyambungkan kalimat sebelumnya dan sesudahnya.

Kemudian, berikut disajikan analisis data dari mahasiswa B7.

(B7, Korea Selatan) Raja Pandu dan Dewi Kunthi ingin memiliki anak. Namun setelah melahirkan, bayi mereka justru terbungkus. Bungkus tersebut sangat susah dibuka. Setelah 8 tahun lamanya, mereka memutuskan mencari pertolongan. Akhirnya bungkus tersebut bisa terbuka.

Hasil tulisan mahasiswa B7 menambahkan konjungsi "namun", "setelah", dan "akhirnya" dalam penulisannya. Dengan demikian, dapat diketahui bahwa konjungsi yang ditulis semakin beragam. Dengan keberagaman konjungsi yang digunakan dalam menulis sinopsis, maka kemampuan menulis mahasiswa BIPA menunjukkan peningkatan yang baik.

Lebih lanjut, selain dalam hasil pembelajaran, respon mahasiswa terkait pembelajaran bahasa Indonesia sebagai bahasa asing dengan media AWAN ASA juga perlu dijelaskan. Hal ini akan menunjukkan bagaimana proses pembelajaran dengan media AWAN ASA ini diterima atau tidak oleh mahasiswa BIPA UNESA. Angket yang disebarkan terdiri atas dua bagian, di mana bagian pertama berisi pertanyaan-pertanyaan seputar pengalaman mengenai lintas budaya yang pernah mereka alami, sedangkan di bagian kedua lebih mengacu pada bagaimana respon mereka terhadap proses pembelajaran. Dua bagian ini dapat menjadi pembanding dalam penelitian ini sehingga didapatkan hasil akhir penelitian yang akurat dan konkret. Berikut ditampilkan tabel hasil angket setelah proses pembelajaran berlangsung.

Tabel 2 Hasil Angket Bagian 1

\begin{tabular}{llc} 
No & \multicolumn{1}{c}{ Pertanyaan } & Persentase \\
\hline 1. & $\begin{array}{l}\text { Anda pernah } \\
\text { melihat } \\
\text { pertunjukan } \\
\text { kebudayaan di } \\
\text { negara asal } \\
\text { Anda. }\end{array}$ & SELALU=14,3\% \\
SERING=28,6\% \\
2.
\end{tabular}




\begin{tabular}{l} 
antara satu PERNAH=42,9 \\
kebudayaan dari \\
suatu negara \\
dengan \\
kebudayaan dari \\
negara lain \\
dalam kelas. \\
\hline Dari tabel di atas, dapat disimpulkan \\
bahwa hasil tertinggi yaitu kategori \\
"Jarang" dengan skor masing-masing \\
kategori $57,1 \%$, 42,9\%, dan 57,1\%. \\
Kategori jarang ini menunjukkan bahwa \\
dalam pembelajaran bahasa, para \\
mahasiswa asing ini jarang sekali melihat \\
pertunjukan kebudayaan, baik dari \\
negaranya sendiri maupun dari negara lain \\
untuk meningkatkan pemahaman dan \\
penguasaan mereka dalam belajar bahasa. \\
Lebih lanjut, hasil ini dapat dibandingkan \\
dengan respon mereka terhadap metode \\
pembelajaran bahasa Indonesia berbasis \\
pengenalan lintas budaya dengan aplikasi \\
AWAN ASA melalui hasil angket bagian \\
kedua sebagai berikut.
\end{tabular}

Tabel 3 Hasil Angket Bagian 2

\begin{tabular}{llc}
\hline No. & \multicolumn{1}{c}{ Pertanyaan } & Persentase \\
\hline 1. & $\begin{array}{l}\text { Pembelajaran lintas } \\
\text { budaya sangat penting } \\
\text { bagi Anda. }\end{array}$ & $\mathbf{S S}=\mathbf{5 7 , 1 \%}$ \\
\hline & $\mathbf{S}=\mathbf{4 2 , 9 \%}$ \\
\hline 2. & $\begin{array}{l}\text { Pelestarian budaya } \\
\text { penting untuk } \\
\text { diintegrasikan dalam } \\
\text { pembelajaran di kelas. }\end{array}$ & $\mathbf{S S}=\mathbf{5 7 , 1 \%}$ \\
\hline 3. & $\begin{array}{l}\text { Pembelajaran } \\
\text { terintegrasi } \\
\text { pengenalan lintas } \\
\text { budaya cukup efektif } \\
\text { bagi penguasaan } \\
\text { bahasa Indonesia } \\
\text { Anda. }\end{array}$ & $\mathbf{S S = 1 0 0 \%}$ \\
\hline 4. & $\begin{array}{l}\text { Metode dan media } \\
\text { yang digunakan } \\
\text { cukup berdampak }\end{array}$ & $\mathbf{S S = 4 2 , 9 \%}$ \\
\hline
\end{tabular}

bagi pemahaman dan $\quad \mathbf{K S}=\mathbf{1 4 , 3 \%}$
pengetahuan Anda
mengenai kebudayaan
Indonesia maupun
kebudayaan dari
negara lain.

Hasil di atas diperoleh skor tertinggi dari masing-masing pernyataan dalam angket yaitu pernyataan pertama dan kedua masing-masing 57,1\% sangat setuju dan $42,9 \%$ menyatakan setuju, pernyataan ketiga $100 \%$ sangat setuju, pernyataan keempat $42,9 \%$ sangat setuju, $42,9 \%$ setuju, serta $14,3 \%$ kurang setuju. Dari hasil ini dapat diketahui bahwa mahasiswa asing sangat menyukai dan mendukung metode dan media dalam pembelajaran yang digunakan.

Terdapat penambahan respon mahasiswa asing dari hasil pengamatan peneliti, yaitu adanya berbagai macam pernyataan yang beragam dari mahasiswa asing terkait dengan metode dan media pembelajaran yang digunakan. Sebagian besar mahasiswa menyatakan bahwa mereka memperoleh banyak kosakata baru dari metode dan media yang digunakan. Lebih lanjut, mereka dapat memahami materi yang disampaikan dengan mudah, lebih asik, dan senang. Adanya penambahan metode diskusi dengan peneliti juga berdampak positif bagi perkembangan pembelajaran mereka. Sedangkan bila ditinjau dari lintas budaya, mereka menambahkan bahwa budaya dan cerita rakyat seperti ini harus tetap dilestarikan dan dapat sesekali untuk diintegrasikan dengan pembelajaran di kelas. Selain dapat meningkatkan pemahaman terkait budaya bahasa target, pengenalan lintas budaya juga meminimalisir terjadinya miskomunikasi atau salah paham antara mereka dengan penduduk asli di negara tempat mereka belajar.

Respon mahasiswa ini selaras dengan pernyataan dari Kusherdyana 
(2018) yang mengemukakan bahwa pengenalan dan pembelajaran lintas budaya sangat penting. Pembelajaran lintas budaya sebagai salah satu upaya individu mengenali dan memahami kebudayaan dari negara lain sehingga dapat mengurangi dampak regresi budaya, meningkatkan dan membangkitkan pengalaman-pengalaman positif antar budaya. Selain itu, dalam pembelajaran ilmu bahasa dan komunikasi, pemahaman lintas budaya akan membantu pembelajar mendapatkan kosakata baru, mempercepat penguasaan bahasa, serta timbulnya komunikasi-komunikasi yang efektif dengan orang-orang baru maupun masyarakat. Hal ini selaras dengan pandangan dari Feiman-Nemser (2010) yang menyatakan bahwa kegiatan belajar mengajar adalah proses sosialisasi. Dengan demikian, Feiman-Nemser lebih condong untuk mempertimbangkan "proses unik pembelajaran sebagai bagian dari bekerja dalam lingkungan budaya baru yang terdiri dari kolega, kurikulum, dan organisasi".

Dengan demikian, pembelajaran dengan metode dan media yang baru dapat dikatakan unik sehingga mampu membawa pembelajar menjadi bagian dari masyarakat. Dalam ranah belajar bahasa, peserta didik dibawa untuk mengenal budaya bahasa target melalui metode dan media aplikasi AWAN ASA, sehingga proses unik pembelajaran ini mampu mendorong mereka untuk memiliki pemahaman yang komprehensif terkait bahasa dan lintas budaya, di mana hal ini selaras dengan pernyataan dari Catana (2014) yang menyatakan bahwa pembelajaran bahasa asing memang seharusnya mendukung untuk meningkatkan pemahaman pembelajar mengenai kesadaran akan mencintai kebudayaan, kemampuan menghindari kesalahan konsepsi antara budaya di negara asal dan negara tujuan, kemampuan untuk lebih berpikiran terbuka, menghargai budaya di negara lain, meningkatkan kepekaan kebudayaan, memperluas pengalaman, menanamkan kesadaran mengenai perbedaan-perbedaan dalam sistem yang ternyata masih bisa dipelajari, serta mampu mempelajari keterampilan berkomunikasi maupun pemecahan masalah sehingga dapat menjadi bekal untuk kehidupannya baik saat kembali ke negaranya sendiri maupun saat masih di negara lain.

Dari pemaparan di atas, dapat diketahui bahwa metode dan aplikasi yang digunakan dalam pembelajaran bahasa Indonesia untuk mahasiswa BIPA UNESA benar-benar sesuai bagi mereka, karena metode dan media yang dipakai dalam pembelajaran bahasa Indonesia berbasis lintas budaya mampu meningkatkan pemahaman dan pengetahuan mereka mengenai bahasa dan kebudayaan Indonesia. Selain itu, dengan mengetahui dan mempelajari budaya target dapat mempercepat kepekaan kebahasaan pembelajar melalui banyaknya kosakata baru.

\section{KESIMPULAN}

Dari penjelasan dan pembahasan di atas dapat ditarik kesimpulan bahwa proses pembelajaran bahasa Indonesia terintegrasi dengan pengenalan lintas budaya adalah dengan 4 langkah utama, yaitu penjelasan awal materi, pembagian dan penggunaan aplikasi AWAN ASA, diskusi lintas budaya dikaitkan dengan pembelajaran bahasa Indonesia, dan penyusunan sinopsis cerita wayang serta penilaian.

Dengan metode dan media aplikasi AWAN ASA yang dipakai dalam pembelajaran bahasa Indonesia terintegrasi dengan pengenalan lintas budaya, didapati hasil keterampilan menulis siswa cukup bagus, dengan ratarata nilai 74 dan mampu menulis konjungsi dari 8-18 kata. 
Selain itu, respon mahasiswa asing terhadap pembelajaran bahasa Indonesia yang terintegrasi pengenalan lintas budaya cukup positif. Hal ini menguatkan pernyataan bahwa dalam pembelajaran bahasa yang terintegrasi pengenalan lintas budaya akan mempercepat penguasaan kebahasaan mereka. Lebih lanjut, dapat disimpulkan bahwa metode dan media yang dipakai dalam pembelajaran ini cukup efektif dan efisien, serta memiliki korelasi lurus dengan tujuan utama pembelajaran.

\section{DAFTAR PUSTAKA}

Artaewee, A. (2018). Peranan Bahasa Indonesia Bagi Mahasiswa Thailand. SENASBASA (Seminar Nasional Bahasa dan Sastra) (hal. 40-46). Malang: Universitas Muhammadiyah Malang.

Arumdyahsari dkk., S. W. (2016). Pengembangan Bahan Ajar Bahasa Indonesia bagi Penutur Asing (BIPA) Tingkat Madya. Jurnal Pendidikan: Teori, Penelitian, dan Pengembangan, 828-834.

Bilyalova, A. (2017). ICT in Teaching a Foreign Language in High School. Procedia - Social and Behavioral Sciences 237, 175-181.

Bobykina, I. (2015). My Philosophy of Teaching Foreign Languages. Procedia, Social and Behaviour Sciences 186, 684-687.

Catana, S. E. (2014). Teaching crosscultural communication issues - a way of successfully integrating into the multicultural knowledge society. Procedia, Social and Behaviour Sciences 128 , 343-348.

Deng dkk., L. (2017). Supporting crosscultural online discussion with formal and informal platforms: a case between Hong Kong and Taiwan. Research and Practice in Technology Enhanced Learning, 115.

Feiman-Nemser, S. (2010). Multiple meanings of new teacher induction. In J. Wang, S. J. Past, present and future research on teacher induction. . Lanham, MA: Rowman \& Littlefield. .

Gonzalez-Acevedo, N. (2016). Technology-Enhanced-Gadgets in the Teaching of English as a Foreign Language to Very Young Learners. Ideas on Implementation. Procedia Social and Behavioral Sciences 232 , 507-513.

Harawati, I. N. (2019). Pembelajaran Bahasa Indonesia Sebagai Bahasa Asing Pertama, Kedua, dan Ketiga. Kongres Bahasa Indonesia. Jakarta: Badan Pengembangan dan Pembinaan Bahasa Kemendikbud.

Klimova, Blanka. (2020). Benefits of the Use of Mobile Applications for Learning a Foreign Language by Elderly Population. Procedia Computer Science Volume 176. 2184-2191.

Kondrateva dkk., I. G. (2015). Technology of Students' Professional Competences Formation While Teaching a Foreign Language. Procedia Social and Behavioral Sciences 191 , 2250-2253.

Kusherdyana. (2018). Pemahaman Lintas Budaya. Bandung: Alfabeta.

Malinovska et al, O. L. (2017). ICT in teaching foreign languages to adult people with acquired severe visual 
impairment. Procedia - Social and Behavioral Sciences 237, 311-318.

Oroujlou, N. (2012). The importance of media in foreign language learning. Procedia - Social and Behavioral Sciences 51, 24-28.

Pourfeiz, J. (2016). A Cross-sectional Study of Relationship between Attitudes toward Foreign Language Learning and Academic Motivation . Procedia - Social and Behavioral Sciences 232, 668-676.

Srisawad dkk., P. (2016). Innovating a constructivist learning model to instill cultural diversity respect into youths in a Thai tourism community. Kasetsart Journal of Social Sciences 37, 88-92.

Sugiyono, P. (2008). Metode Penelitian Kuantitatif Kualitatif dan $R \& D$. Bandung: Penerbit Alfabeta.

Suryaman, M. (2010). Media Pembelajaran Bahasa Indonesia. Yogyakarta: Workshop Pengembangan Kompetensi Guru SMK di DIY 28 Juli 2010. 